\title{
The Research and Practice of Engineering Practice Ability Strategies with Computer Professional Education Based on CDIO
}

\author{
Wu XiuQin \\ School of Computer \& Information Technology of \\ Northeast Petroleum University \\ DaQing, China \\ e-mail: wxqltl@163.com
}

\author{
Liu TieLiang \\ School of Computer \& Information Technology of \\ Northeast Petroleum University \\ DaQing, China \\ e-mail: ltldqpi@163.com
}

\begin{abstract}
CDIO is the newest research result of international engineering education reform in recent years. This article will explore the new system of integration which about CDIO and engineering practice ability for computer professional education. Be aimed at the main problem that the engineering practice training mode with computer professional education for current students of university, it proposed the new computer professional engineering practice training strategy in several areas such as curriculum, training projects and team building based on CDIO philosophy, in addition, it practiced the training strategy, and achieved well results.
\end{abstract}

Keywords- CDIO; Engineering Education; Education Reform; Computer Professional Education

\section{INTRODUCTION}

Since the Industrial Revolution, engineering and technical personnel has played a huge role in promoting of the national economic and technological progress. Whether it has a large number of the high-quality engineering talent has become the important factor of effecting national core competencies. In recent years, as a typical engineering academics, the computer profession education is being subjected to the thought of science has absolute predominance than engineering, it emphasizes theory study too much, doesn't attach importance to engineering practice and synthesis capability. It needs more to carry on innovating with education idea and reforming with teaching mode.

CDIO denotes Conceive, Design, Implement and Operate, it is the newest research result of international engineering education reform in recent years, it not only inherits but also develops the idea of European and American engineering education reform more than twenty years [1]. Even more important, it proposed systematic ability cultivation, comprehensive implementation guide, complete implement process and rigorous inspection including twelve standards and has strong operability. The theory of "learning-bydoing" and "Item-Based educate and study" focus on summary and abstract expression with R\&D and product operation as its carrier, so that students can learn in the way of active and practical courses which link to learn engineering[2]. CDIO philosophy is in line with our major of computer engineering practice on capacity-building for reform.

\section{THE STATUS AND PROBLEMS WITH THE ENGINEERING PRACTICE ABILITY IN CURRENT COMPUTER PROFESSIONAL EDUCATION}

China's current computer professional education model is still in a traditional subject-based professional education, this model train the students with more heavy theory of light practice, lack of team spirit and innovation consciousness. With the employment aspects of IT companies continue to mature and rational, they have formed the integrated requirements gradually for the professional skills, project experience and professional quality, and urgently require for fostering out computer professionals with modern software engineering environment for the survival and growth of lifelong learning ability, team cooperation and communication skills, operational capacity of large projects, this led to the disconnection between the education and social needs. At present, college computer professional education with the engineering practice ability exist much questions.

\section{A. Curriculum Content is Distributed, Lack of Engineering Coherence Between the Courses}

The computer specialty course has a strong practicality; however, in the existing training system it is divided simply according to the content of the course teaching units, the students have no clear realistic goals in the process of learning, and lack of landmark intermediate link. Conventional practice mode, such as computer experiment, curriculum design and training practice, is set in separately for specific teaching knowledge or specific courses practice target, and limited itself in fixed classroom theoretically, as the result, it results in the lack of consistency in practice process. In practice, either the goal or the content, the student is one-sided, and the system of practicing is not coherent, it is out of the question for gearing to the employment or for gearing to the practicing training.

\section{B. Lack of the Practical Engineering Training in the Engineering Education, Be Weak to Practice}

Engineering training is essential for higher engineering education, but in recent years, the practice teaching of many colleges is weakened in varying degrees, the proportion of experimental course is decreased, and the opportunity for the students to practice is reduced, these all make the engineering training could not reach the minimum 
requirements, and seriously effect quality of engineering education[3]. Currently, it makes the engineering education become armchair strategist with these reasons, such as the engineering education is basically completed in school and doesn't contact the enterprise closely, curriculum design, graduate design escape from engineering physically, there is the tendency to heavy theory of light practice in the process of practice teaching, and so on.

\section{Teachers Lack of the Experience and Ability of Engineering Practice}

Currently, the typical teachers for engineering education are lack of practice of engineering and production experience, and there is not much engineers with rich practical experience to teach in the university. Many teachers of engineering colleges mostly come from graduate student, and many of them walk up to the podium after graduation, directly become the student to the teacher. although these young teachers with higher academic qualifications and deep professional knowledge, because of scarcity with practice experience, they can not take the actual problem with the industry to enrich the course content, or quote from the engineering example to elaborate basic theory and principle while teaching professional lesson, these disadvantages against to improving the quality of engineering education[4].

\section{BUILD THE ENGINEERING PRACTICE ABILITY STRATEGY FOR COMPUTER PROFESSION BASED ON CDIO CONCEPT}

CDIO is the system of integrity, it is the quintessence of implementation with the project from the design to the engineer and the essence for engineer with comprehensive ability[5]. CDIO not only pays attention to the study of foundation knowledge with the students, but also more emphasize the applying capability, teamwork ability and the ability to adapt to large-scale system. This article will be aimed at the main problem that the engineering practice training mode with computer professional education for current students of university, it proposed the new computer professional engineering practice training strategy in several areas such as curriculum, training projects and team building based on CDIO philosophy[6].

\section{A. Reform the Content of Curriculum, and Realize the} Expansion from the Classroom Teaching to Engineering

CDIO education model takes the industry demand as orientation, takes measures to synchronize the contents or methods of teaching with the industrial development, takes the training with qualifying the industrial development as the goal of engineering talent[7].In the process of reforming education based on CDIO philosophy, it proposes to take the ideas that "integration" or " integrated " to build the content and structure of curriculum, changes "Curriculum platter " for the integration of the engineering courses, to the question that college computer course content is distributed, lack of coherence in engineering. To the composition of the knowledge, not only emphasize the knowledge factor and unit, but also emphasize the correlation in the professional knowledge system.
- Add innovation teaching courses. The first step of innovation is to build innovative thought, we can penetrate into student with innovate thinking and teach them innovative methodology through a series of courses. Students can get some experiences through their understanding and practice so as to promote their passion to innovate and carry out new action. According to this, we have started some innovation thought and method training courses such as "Innovative thinking and innovative techniques".

- Integrate of existing courses. Due to our adoption of the " $3+1$ " training model, students have to finish all subjects. If the course arrangement is not proper, then it can lead students to spend most of their time in preview, class listening, homework, experiment report and exam and other sessions like these, and as a result, they will have less time to thinking separately and participate in innovation programs. In order to provide students with more time to think and take part in innovation programs, we have integrated part of the professional classes. The purpose for this measure is to offer students more free time in what they are interested in or enter the lab to work on some innovation programs.

- Elaborate design of teaching content of professional core courses. Taking professional courses is an important way to train professional ability. As for the theory-focused courses, we do it in class and make a exploratory learning based on questions. For the practice-focused courses we do it with a method based on complete cases. And for the comprehensive practical courses such as the course design, it needs enterprise actual training. Taking actual or virtual enterprise programs as subjects, and analyzing and designing the program taking them as the main body, students can practice to analyze independently and solve the problems. If the program is a little bigger, there is another way to practice the ability of solving problems as well enhance team spirit, and it is group students to develop the program.

- Reform assessment method and evaluation standard. Reforming assessment method and evaluation standard, we record and track the whole process of the study on some course instead of commenting a student's study effect just by a piece of test paper. We make a whole check about students' study ability, practice ability, analyzing and solving problem ability, and pay attention to study process and effect.

\section{B. Strengthen the Practice Teaching, Increase the Intensity of Engineering Training}

The concept of CDIO emphasizes that students would "learn by doing", and emphasizes the engineering practice[8].Provide students with a good way of learning theory with practice, we can make up for lack of theoretical teaching. The practice that we demand is complete in the whole process of projects, rather than be content with the commonplace, fragmented learning tests or technical training. 
However, it is heavily influenced by the economic situation of universities and the educational strength of the objective factors in the implementation, and difficult to provide students with training opportunities and conditions. Therefore, we can make use of existing resource in the high school, strengthen practical teaching and increase the intensity of engineering training as follows.

- Construct the Innovation Lab, improve the student's ability of engineering practice. The establishment of the Innovation Lab provides a stage for training the student`s project practical ability. We can construct the Innovation Labs in different research according to the professional characteristics, and guide the students by the teachers with strong research capabilities. In the Innovation Labs, students have the self-management and they will complete the design scheme independently or collaboratively, all of these would train the students with the integrative capability of analyzing or solving the complicated practical problem.

- Encourage students to participate in real research projects. School should guide and encourage students to actively take part in the teacher's research project, train the students with innovative spirit and practical ability rely on the project. Participation in research projects is to carry out the process of research training; it can train the students with the capability of identifying problems, asking questions and solving problems, and improve the students practicing ability and innovative ability with integrating theory with practice. Through participation in research projects, students can learn subjects of the latest research trends in time and recognize own search direction as early as possible according to the interest.

- Organize the students to participate in engineering practice, continuously broaden their horizons by this way. Let the students learn something other than textbooks in the contacting with the front-line enterprise personnel, experience their dedication, innovation and professionalism, develop the student's engineering consciousness and professional qualities, stimulate their desire to take the initiative to improve themselves, and make their thoughts be sublimated in the fulfillment.

- Attach importance to graduation project. Graduation project is a "real demonstration" before the students out of the ivory tower and into society, and it is an important step to train the students with innovation capability and practicing ability. In the process of completing the graduation project, require the instructor not only to guide students to read a lot of professional journals, extensively access to relevant literature, but also to provide valuable advice to the students about the design idea or design methods, and inspire students to give full play to creative spirit, guide students to improve their innovation capabilities in the practicing.

\section{CONSTRUCT THE HIGH-QUALITY TEACHING STAFF WITH THE CAPABILITY OF INTEGRATING THEORY WITH PRACTICE}

Teacher is the most important part of the education chain, this is means that teachers' quality is the key to evaluate teaching level and quality .To develop outstanding engineering technology talents, a great "double tutorial” teachers' team with rich teaching experience and engineering experience. In the construction of teachers' team, we have to pay attention to personal comprehensive ability, team cooperation spirit and the collective sense of honor, etc of the quality of the construction, these include the training of teachers' love to students, enthusiasm to teaching, perseverance to research, confidence to oneself, deeply loves to the education career, and dedicating his life to professional development. Through the combination of training and introduction and the one of full-time and part-time, we want to build a competent teachers' team for outstanding engineers reserve personnel training. Teachers' team consists of the professional teachers, enterprise part-time professors and external teachers. With the professional teachers and enterprise part-time professor as the main body, external teachers for help, we have formed a high scientific research level, excellent and stable high-quality teachers' team with strong teaching power and rich project management experience.

As to the question that the teachers in the college of engineering are lacking of engineering fulfillment training and lacking of innovation consciousness, we should strengthen the construction of the teacher. On the one hand, efforts to attract a large number of social production personnel with experienced engineering practice to enrich teachers; Universities should also cooperate with the enterprise, send teachers to visit, practice or research with the factory and company, select some teachers to participate the building of experiment and practice base, all of these will enhance the teacher with practical ability and engineering technology applications, improve the relevance and application of teaching, and help to train the "double-quality teachers". On the other hand, requires teachers to change the concepts of education, foster innovative education, personally stand at the forefront of innovation to educate and guide students.

\section{REFERENCES}

[1] Gu PeiHua and Shen MinFen, "Rethinking Engineering EducationThe CDIO Approach”, Academic Press, Beijing:2009,pp.10-35.

[2] Cha JianZhong, "A New Direction for Teaching Reform in Colleges and Universities”, Higher Education of Sciences, Beijing: 2009, pp.912.

[3] Wang Gang, "CDIO engineering education Reading and Thinking Mode”, Higher Education of Sciences, Beijing: 2009, pp.86-87.

[4] Chen XuHui,"Education Model of Computer Engineering Based on CDIO”, Computer Education, Beijing:2010, PP.141-143.

[5] Shen Qi. "Education Model of Computer Engineering Based on CDIO”, Higher Education of Sciences, Beijing: 2009, pp.57-60.

[6] Wang Gang, "Engineering Education Reading and Thinking Mode”, Higher Education of China, Beijing: 2011, pp.86-87. 
[7] Yang Jie, "Exploration of China Higher Engineering Education Undergraduate Teaching Management and Countermeasure”, Northeastern University:2011, pp. 23-38.
[8] Fu Jing, "Research on the Training Mode Reform in the Higher Engineering Education”, Dalian University of Technology:2010, pp.4-16. 